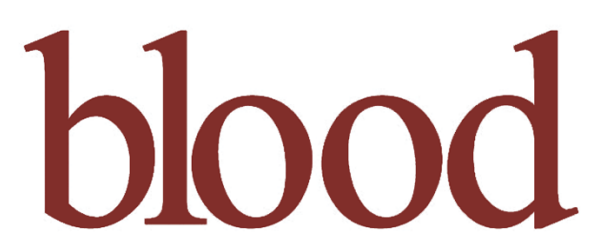

2009 113: 1422-1431

Prepublished online Dec 4, 2008;

doi:10.1182/blood-2008-09-177139

\title{
Engineering human hematopoietic stem/progenitor cells to produce a broadly neutralizing anti-HIV antibody after in vitro maturation to human B lymphocytes.
}

Xin M. Luo, Emily Maarschalk, Ryan M. O'Connell, Pin Wang, Lili Yang and David Baltimore

Updated information and services can be found at:

http://bloodjournal.hematologylibrary.org/cgi/content/full/113/7/1422

Articles on similar topics may be found in the following Blood collections:

Hematopoiesis and Stem Cells (2481 articles)

Immunobiology (3738 articles)

Gene Therapy (406 articles)

Information about reproducing this article in parts or in its entirety may be found online at:

http://bloodjournal.hematologylibrary.org/misc/rights.dt|\#repub_requests

Information about ordering reprints may be found online at:

http://bloodjournal.hematologylibrary.org/misc/rights.dtl\#reprints

Information about subscriptions and ASH membership may be found online at:

http://bloodjournal.hematologylibrary.org/subscriptions/index.dtl

Blood (print ISSN 0006-4971, online ISSN 1528-0020), is published semimonthly by the American Society of Hematology, 1900 M St, NW, Suite 200, Washington DC 20036.

Copyright 2007 by The American Society of Hematology; all rights reserved.

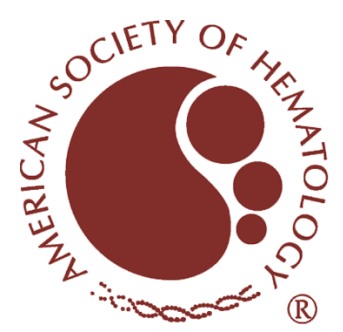




\title{
Engineering human hematopoietic stem/progenitor cells to produce a broadly neutralizing anti-HIV antibody after in vitro maturation to human B lymphocytes
}

\author{
Xin M. Luo, ${ }^{1}$ Emily Maarschalk, ${ }^{1}$ Ryan M. O'Connell, ${ }^{1}$ Pin Wang, ${ }^{2}$ Lili Yang, ${ }^{1}$ and David Baltimore ${ }^{1}$ \\ 'Division of Biology, California Institute of Technology, Pasadena; and 2Mork Family Department of Chemical Engineering and Materials Science, University of \\ Southern California, Los Angeles
}

\begin{abstract}
Broadly neutralizing anti-HIV antibodies are rare and have proved hard to elicit with any immunogen. We have tested in vitro the notion that such antibodies or other antiviral proteins could be made by lentivirus-mediated gene transfer into human hematopoietic stem/progenitor cells (HSPCs), followed by differentiation of the transduced cells into $B$ cells, the most potent antibody-producing cells. To do this, we have developed a highly efficient
\end{abstract}

system for in vitro maturation of secreting $B$ lymphocytes and plasma cells from CD34 ${ }^{+}$HSPCs. It is a 3-stage, in vitro culture system that supports normal human B-lineage development from HSPCs to antibody-secreting plasmablasts $(\sim 36 \%)$ and plasma cells $(\sim 20 \%)$. By transducing human cord blood CD34+ cells with lentiviral vectors encoding a secretory monoclonal anti-HIV antibody, b12 $\left(\operatorname{lgG}_{1}\right)$, we were able to program hu- man B cells to produce in vitro up to $1.5 \mu \mathrm{g} / \mathrm{mL}$ of this broadly neutralizing antibody. Our results suggest that an HIV vaccine might be delivered by autologous transplantation of in vitro-programmed HSPCs, which would develop into antibody-secreting B cells in vivo and provide a continuous supply of anti-HIV neutralizing antibodies. (Blood. 2009;113: 1422-1431)

\section{Introduction}

It is widely agreed that the most effective method to slow the AIDS epidemic is a vaccine. ${ }^{1,2}$ However, human efficacy trials of vaccine candidates designed to elicit either antibody- or T cell-based immunity have failed. ${ }^{3,4}$ Elicitation of antibodies is the apparent mode of protection for most vaccines and would be the mode of choice for an HIV vaccine. Thus, if a method to produce high titer HIV-specific neutralizing antibodies in persons at risk for AIDS could be developed, infection and subsequent disease on exposure to HIV could be prevented. Because HIV has evolved to be highly resistant to antibody neutralization ${ }^{5}$ and all attempts to design an immunogen that would raise a broadly neutralizing response have thus far failed, ${ }^{6}$ a new approach, even a far-fetched one, is clearly desirable.

One possibility would be to produce an anti-HIV antibody using protein design methods or in vitro screening. However, were such an approach to be successful, the protein molecule might be valuable as a therapeutic but could not be a prophylactic except by constant administration. But the body's B lymphocytes are dedicated producers of antibodies, so if they could be programmed to make a protective antibody, this might prove a valuable asset in preventing the spread of AIDS. Such a method might also be valuable for delivering other proteins of therapeutic importance.

Developing such a methodology is a challenge. One would have to find valuable proteins, know how to program the cells to make the antibody, preferably have the protective protein made on demand, be quite certain of the safety of the method, and make the process cost-effective, particularly in the context of Africa. We have undertaken this enterprise. We report here our first successful step, the programming of human B cells to make a predefined antibody.
For our initial work, we have chosen a known, broadly reactive human monoclonal neutralizing antibody, b12, one that neutralizes many primary isolates of different genetic subtypes of HIV- $1 .^{7}$ It recognizes the CD4 binding site on the viral gp120 glycoprotein. ${ }^{8,9}$ It has been confirmed that b12 can neutralize clades B, C, and D primary isolates as tested in vitro ${ }^{7,10}$ and protect against immunodeficiency virus infection in vivo. ${ }^{11,12}$ B12 variable regions were originally screened out from a phage-display library, ${ }^{13}$ and we have made them into a human $\operatorname{IgG}_{1}$. Because we must work with human cells, we have chosen to test our procedure using an in vitro culture system. Although there are systems constructed for in vitro maturation of murine B cells, there is little work with human systems and no report of successful engineering of human hematopoietic stem/progenitor cells (HSPCs) to generate cells that secrete significant amounts of a defined antibody. Here, we report the programming of human B cells to produce more than $1 \mu \mathrm{g} / \mathrm{mL}$ of b12- $\operatorname{IgG}_{1}$ using a 3-stage, in vitro culture system that supports normal human B-lineage development from HSPCs to antibodysecreting plasmablasts and plasma cells.

\section{Methods}

\section{Plasmid construction}

The light and heavy chain variable sequences of b12 were amplified and inserted upstream of the human $\kappa$ chain constant and secretory $\mathrm{IgG}_{1}$ constant regions, respectively. The 2 resulting genes were linked via F2 $\mathrm{A}^{14}$ and subcloned into the FUW lentiviral vector ${ }^{15}$ to create U-b12. In addition, we constructed the FMHW lentiviral vector by replacing the ubiquitin-C promoter in FUW with human $\mu$ heavy chain promoter preceded by $\mathrm{E} \mu$
Submitted September 3, 2008; accepted November 20, 2008. Prepublished online as Blood First Edition paper, December 4, 2008; DOI 10.1182/blood-2008-09177139.

The online version of this article contains a data supplement.
The publication costs of this article were defrayed in part by page charge payment. Therefore, and solely to indicate this fact, this article is hereby marked "advertisement" in accordance with 18 USC section 1734.

(C) 2009 by The American Society of Hematology 
enhancer flanked by matrix association regions (MARs). Similarly, we constructed the FEEKW vector where the ubiquitin-C promoter was replaced by human $\kappa$ light chain promoter preceded by enhancers and MARs. The bicistronic unit of b12 was then subcloned into FMHW and FEEKW to create MH-b12 and EEK-b12, respectively. For test purposes, we also created vectors expressing green fluorescent protein (GFP). All constructs were tested in Nalm-6 (pre-B), Ramos (naive B), Dakiki (plasmacytoma), and Jurkat cell lines before being introduced into human HSPCs.

\section{Lentiviral transduction}

Lentiviruses were generated by transfection of HEK-293T cells through calcium phosphate precipitation. ${ }^{16}$ To prepare high-titer viruses, viral supernatant was concentrated by ultracentrifugation (Optima L-80K ultracentrifuge; Beckman Coulter, Fullerton, CA) for 90 minutes at $50000 \times g$. Human cord blood CD34+ ${ }^{+}$HSPCs were purchased from AllCells (Emeryville, CA) and maintained for less than 24 hours before infection in Iscove modified Dulbecco medium containing $10 \%$ fetal bovine serum and cytokines. The cytokines included human recombinant interleukin-3 (IL-3; $10 \mathrm{ng} / \mathrm{mL})$, Flt3 ligand $(10 \mathrm{ng} / \mathrm{mL})$, thrombopoietin $(10 \mathrm{ng} / \mathrm{mL})$, stem cell factor (SCF; $5 \mathrm{ng} / \mathrm{mL}$ ), and granulocyte-colony stimulating factor (G-CSF; $5 \mathrm{ng} / \mathrm{mL}$ ) and were given every other day during the infection. All cytokines were obtained from R\&D Systems (Minneapolis, MN) except for Flt3 ligand (eBioscience, San Diego, CA). Two sequential infections of 0.3 to $0.4 \times 10^{6} \mathrm{HSPCs} /$ well by concentrated lentiviral particles at multiplicity of infection of 1000 were carried out in 48-well plates precoated with Retronectin (Takara, Kyoto, Japan) at $50 \mu \mathrm{g} / \mathrm{mL}$. HSPCs were collected 3 days after infection and analyzed by flow cytometry. The infected cells maintained their progenitor phenotype.

\section{In vitro human B lymphopoiesis culture system}

Our culture system was extensively modified from the system of Fluckiger et $\mathrm{al}^{17}$ for better generation of $\mathrm{CD} 19^{+}$cells and plasma cells. HSPCs were first primed for 5 days (stage 1) to commit to B-lineage development in the presence of IL-3, Flt3 ligand, thrombopoietin, SCF, and G-CSF. MS5 cells were plated at $3 \times 10^{4}$ cells/well in 24 -well plates overnight. Human HSPCs transduced with lentiviral vectors or no-virus control cells were seeded onto the MS5 monolayer at $6 \times 10^{4}$ cells $/ 500 \mu \mathrm{L}$ per well in Iscove modified Dulbecco medium containing $5 \%$ fetal bovine serum. The coculture (stage 2) was maintained with biweekly feeding for 5 to 6 weeks, once with the addition of $500 \mu \mathrm{L}$ of medium and the other time with the removal of $80 \%$ of cells after gentle agitation and adding back $300 \mu \mathrm{L}$ of medium. After stage 2, cells were counted and seeded at $5 \times 10^{4}$ cells/500 $\mu \mathrm{L}$ per well in 48 -well plates precoated with MS5 stably transduced to express low or high levels of human CD40L on the surface (MS40L cell lines). The human CD40L clone was obtained from Origene (Rockville, MD) and subcloned into FUW. MS5 cells were transduced by FUW-CD40L virus, and MS40L single clones were selected by flow cytometry to generate MS40L-high and MS40L-low cell lines. Stage 3 was carried out on the MS40L monolayer for 2 to 3 weeks in the presence of $10 \mathrm{ng} / \mathrm{mL}$ of IL-2 (R\&D Systems), $100 \mathrm{ng} / \mathrm{mL}$ of IL-10 (eBioscience), and $2 \mu \mathrm{M}$ CpG (ODN-2006; synthesized by Integrated DNA Technologies, Coralville, IA). In some experiments, IL-6 (50 ng/mL; R\&D Systems), soluble CD40L ( $1 \mu \mathrm{g} / \mathrm{mL})$, and a cross-linking enhancer $(2 \mu \mathrm{g} / \mathrm{mL}$; Alexis Biochemicals, San Diego, CA) were also used.

\section{Enzyme-linked immunosorbent assays}

Total human $\operatorname{IgM}$, IgG, and $\operatorname{IgA}$ were assayed using commercial enzymelinked immunosorbent assays (ELISA) kits (Bethyl Laboratories; Montgomery, TX). The ELISA to detect b12- $\operatorname{IgG}_{1}$ was modified from Selvarajah et al. ${ }^{18}$ Briefly, plates were coated overnight at $4{ }^{\circ} \mathrm{C}$ with monomeric gp $120_{\mathrm{MN}}$ at $2 \mu \mathrm{g} / \mathrm{mL}$ in phosphate-buffered saline (PBS). Wells were washed with PBS containing $0.05 \%$ Tween-20 (PBS-T) and blocked with 3\% bovine serum albumin (BSA) for 1 hour at room temperature. After BSA was aspirated, dilutions of samples and b12 standard in PBS-T containing 1\% BSA were added and incubated at $37^{\circ} \mathrm{C}$ for 3 hours. The b12 standard medium was obtained by transfecting $293 \mathrm{~T}$ cells with U-b12, and its concentration was determined by Biacore gp120-binding assay (Biacore T100 biosensor system; GE Healthcare, Little Chalfont, United Kingdom). Wells were washed again, and goat antihuman $\operatorname{IgG~F}\left(\mathrm{ab}^{\prime}\right)_{2}$ conjugated with horseradish peroxidase (Pierce Biotechnology, Rockford, IL) diluted 1:1000 was added and incubated for 1 hour at $37^{\circ} \mathrm{C}$. Plates were developed by the

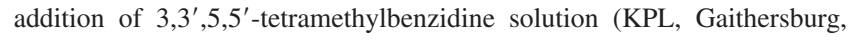
$\mathrm{MD})$. The reaction was stopped by adding $2 \mathrm{M} \mathrm{H}_{2} \mathrm{SO}_{4}$, and plates were read at $450 \mathrm{~nm}$ on a SpectroMax Reader (Molecular Devices, Sunnyvale, CA).

\section{Detection of virus integration}

Provirus copy numbers were determined by a modified Alu-long terminal repeat (LTR) nested-polymerase chain reaction (PCR) protocol. ${ }^{19,20}$ Briefly, the first round of PCR allowed the amplification of up to $3 \mathrm{~kb}$ between an Alu sequence (Alu-fw: $5^{\prime}$-TCCCAGCTACTGGGGAGGCTGAGG-3') and a sequence immediately downstream of $5^{\prime}$-LTR after the virus is integrated (PBS-bw: 5'-GAGTCCTGCGTCGAGAGAG-3'). The second round used SYBR green-based quantitative PCR (7300 Real-Time PCR system; Applied Biosystems, Foster City, CA) to detect a 143-bp sequence of the provirus LTR (late-RT-fw: 5'-TGTGTGCCCGTCTGTTGTGT-3'; and lateRT-bw: 5'-GAGTCCTGCGTCGAGAGAGC-3'). To establish the standard curve, an integrated gDNA standard was generated by extracting gDNA from a stable THP-1 cell line with integrated FUW that has been maintained for 6 months, and the provirus copy number in the standard gDNA was determined using serial dilutions of linearized FUW plasmid with known numbers of LTR copies. Genomic DNA of a THP-1 line transduced with an irrelevant vector was used as the negative control. $\beta$-Globin was used as the loading control. The detection range of this Alu-LTR nested-PCR protocol was 500 to $6 \times 10^{4}$ copies per $50 \mathrm{ng}$ gDNA. The correlation between the amount of gDNA and the cell number at different stages of B-cell development was determined experimentally.

\section{Results}

\section{Improvement of the in vitro human B lymphopoiesis culture system}

To produce a system that will support production of a defined antibody, we first optimized human B-cell generation and antibody production from unmodified human HSPCs. We used purified $\mathrm{CD} 4^{+}$cells from human cord blood as our starting material, recognizing that such cell populations are enriched for stem cells but by no means pure. We call these cells HSPCs to recognize that the cell population has both stem cells and progenitor cells that might already be committed to the lymphoid lineage.

During normal hematopoiesis, B-cell populations are generated from hematopoietic stem cells in the bone marrow and activated to become plasma cells and memory cells in the periphery/spleen. Previous murine and human B lymphopoiesis culture systems have included separate culture stages to mimic the bone marrow and peripheral/splenic stages of B-cell development, and we followed that precedent. We summarize here the system we have developed and its properties. The experimental justification for the statements made here will be presented when we discuss lentivirally transduced cells. We started with a published human system ${ }^{17}$ and made these modifications: (1) We added a step of HSPC priming for 5 days as our stage 1 for B-cell lineage commitment using IL-3 and Flt3 ligand, ${ }^{21}$ thrombopoietin, ${ }^{22}$ and SCF and G-CSF. ${ }^{23}$ (2) In our stage 2, murine stromal MS5 cells that provide the B-lineage growth factor IL-723,24 were used to support the sequential generation of human pro-B, pre-B, and immature B cells, replacing the S17 cells used in the previous system. (3) For our stage 3, we developed a novel cocktail of IL-2, IL-10, and CpG, in conjunction with transformed MS5 cells providing a low level of anchored 


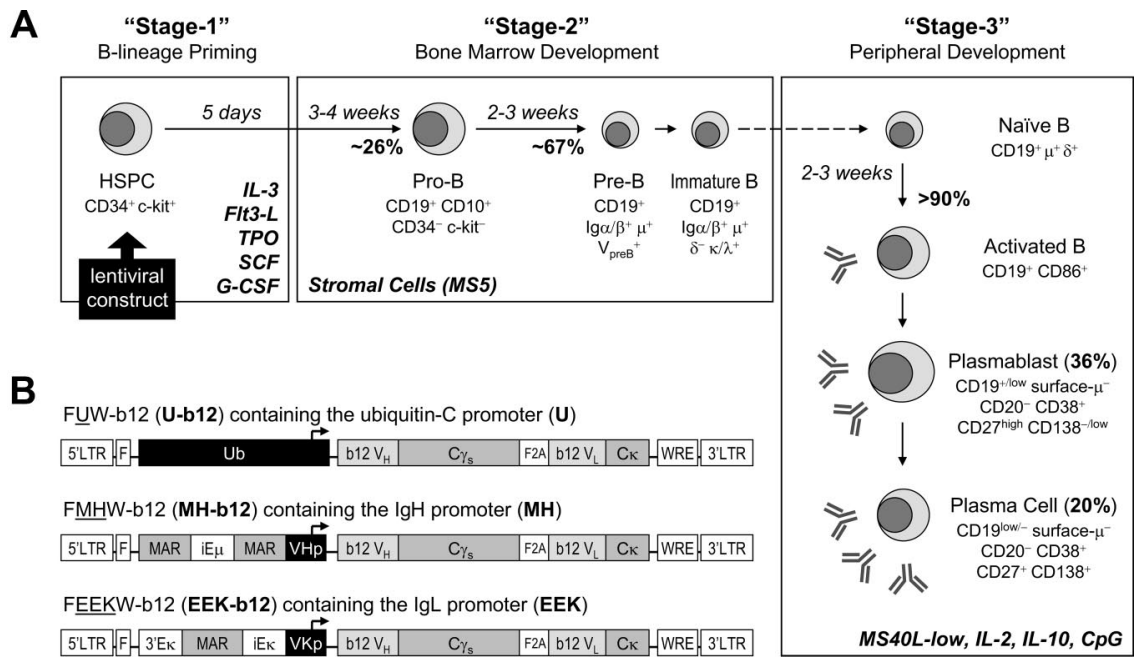

Figure 1. Engineering human HSPCs to produce b12, a broadly neutralizing antibody against HIV-1 gp120, after in vitro maturation to $B$ lymphocytes. (A) A 3-stage, in vitro human $B$ lymphopoiesis culture system was established. Lentiviral constructs were introduced to the HSPCs to achieve B-cell programming. During the 5 days of stage 1, IL-3 (10 ng/mL), Flt3 ligand (Flt3-L; $10 \mathrm{ng} / \mathrm{mL})$, thrombopoietin (TPO; $10 \mathrm{ng} / \mathrm{mL})$, SCF $(5 \mathrm{ng} / \mathrm{mL})$, and G-CSF $(5 \mathrm{ng} / \mathrm{mL}) \mathrm{primed}$ the HSPCs for B-lineage commitment. The 6-week stage 2 used stromal support (MS5) and generated a mixture of pre-B and immature B cells from CD34 ${ }^{+}$HSPCs. The 3 -week stage 3 promoted B-cell activation, proliferation, and differentiation into antibody-secreting plasmablasts and plasma cells by the presence of IL-2 (10 ng/mL), IL-10 (100 ng/mL), CpG (2 $\mu \mathrm{M})$, and MS5 cells stably expressing a low level of CD40L (MS40L-low cells). The surface markers at different stages of B-cell development are shown. (B) Three lentiviral constructs were generated that carried the secretory form of b12-lgG ${ }_{1}$ driven by either the ubiquitin-C (U-b12), Ig heavy chain (MH-b12), or Ig light chain promoter (EEK-b12). The MH promoter contained the human $\mu$ chain promoter (VHp) preceded by the $\mathrm{i} \mathrm{E}_{\mu}$ enhancer flanked by matrix association regions (MAR). The EEK promoter contained the $\kappa$ light chain promoter (VKp) preceded by an intronic enhancer ( $\left(\mathrm{E}_{\kappa}\right)$, an MAR, and a $3^{\prime}$ enhancer ( $\left.3^{\prime} \mathrm{E}_{\kappa}\right)$. The secretory $\gamma\left(\gamma_{\mathrm{s}}\right)$ heavy chain and $\kappa$ light chain genes with b12 variable regions were linked through F2A (2A sequence from foot-and-mouth disease virus) sequences. LTR indicates long terminal repeats; F, HIV-1 flap element; WRE, woodchuck hepatitis virus posttranscriptional regulatory element.

CD40L (MS40L-low), which supported B-cell activation, replacing the stimulations described in the previous system. ${ }^{17}$ The growth factors that promoted B-lineage commitment also facilitated lentiviral transduction (data not shown), but they did not further increase the effect of MS5 on B-cell development and were thus excluded from stage 2 . The improved in vitro human B lymphopoiesis culture system is outlined in Figure 1A. In 10 separate experiments, we found $23 \%$ to $28 \%$ of pro-B cells after culturing primed CD34 ${ }^{+}$HSPCs for 3 to 4 weeks on MS5 cells and $65 \%$ to $69 \%$ of $\mathrm{CD} 19^{+}$cells representing a mixture of pre-B and immature $\mathrm{B}$ cells after another 2 to 3 weeks of incubation. Once these cells were moved to stage 3 , within 2 to 3 weeks, $90 \%$ of cells were activated B cells, including antibody-secreting plasmablasts $(35 \%$ $37 \%)$ and plasma cells (16\%-23\%). The percentages of B-cell subpopulations we generated were much higher than previously reported, where only $5 \%$ to $15 \%$ of $\mathrm{CD} 19^{+}$cells were generated during the bone marrow stage, and they failed to differentiate into plasmablasts or plasma cells capable of producing high levels of antibody, ${ }^{17}$ indicating that our method provides a more favorable environment for B-cell development. With this improved human B lymphopoiesis culture system in hand, we could next test the concept of using human $\mathrm{CD} 4^{+}$cell programming to produce B cell-based HIV vaccines.

\section{Stage 1 priming for B-lineage commitment and programming of human B cells through lentiviral transduction of HSPCs}

We targeted $\mathrm{CD} 34^{+}$cells for B-cell programming because the stem cell component among these cells could, in the body, provide a continuous and lifelong supply of programmed B cells. To test viral transduction, we used a GFP-encoding lentiviral vector, FUGW. ${ }^{15}$ $\mathrm{CD} 4^{+}$cord blood cells were mixed with Retronectin as a bridge between the virus and the cells. A transduction efficiency of more than $80 \%$ of $\mathrm{CD}_{3} 4^{+}$cells was achieved after 5 days of incubation in the priming mixture of factors that support progenitor cell growth and commitment to the B-cell lineage, namely, IL-3, Flt3 ligand, thrombopoietin, SCF, and G-CSF (Figure S1A, available on the Blood website; see the Supplemental Materials link at the top of the online article). We also found a similar transduction efficiency when gating on $\mathrm{CD} 34^{+} \mathrm{CD} 38^{-}$cells, a rare and particularly primitive subpopulation of $\mathrm{CD} 34^{+}$cells in human cord blood. ${ }^{25}$

The experimental lentiviral constructs used to produce secretory b12-IgG $\mathrm{Ig}_{1}$ were created as a bicistronic unit containing secretory $\gamma 1$ heavy chain and $\kappa$ light chain, bearing, respectively, the heavy and light variable regions of b12, and the 2 chains were linked by a self-cleaving F2A peptide ${ }^{14}$ (Figure 1B). The linked genes were then subcloned into lentiviral vectors containing either the ubiquitin-C promoter (U) or B cell-specific promoters ( $\mathrm{MH}$ or EEK). The latter 2 we produced: the $\mathrm{MH}$ promoter contained $\mathrm{E} \mu$ enhancer and MAR upstream of human $\mu$ heavy chain promoter, and the EEK promoter consisted of a $3^{\prime}$ enhancer, an MAR, and an intronic enhancer upstream of human $\kappa$ light chain promoter. When vectors bearing these 3 promoters were transfected into 2 human B-cell lines (Nalm-6 and Ramos) and a T-cell line (Jurkat), the ubiquitin-driven constructs expressed b12-IgG $\mathrm{Ig}_{1}$ in both Band T-cell lines, whereas the B cell-specific promoters led to strong expression in B cells but little in T cells (Figure S1B). For test purposes, we also created vectors using these promoters that expressed GFP. In addition, to confirm the functionality of the b12- $\mathrm{IgG}_{1}$ produced by our F2A-containing bicistronic lentivectors, we verified the expression and assembly of b12 heavy and light chains under reducing and nonreducing conditions (Figure S1C) and the HIV-neutralizing ability of b12- $\mathrm{IgG}_{1}$ using the pseudovirus neutralization assay (Figure S1D).

\section{Stage 2 development of human B cells on MS5 stromal cells from primed HSPCs}

To characterize stage 2 , we compared mock-infected $\mathrm{CD} 34^{+}$cells and ones infected with b12-expressing lentiviruses. No differences were evident. As the cells were incubated with MS5 cells, they lost CD34 and c-kit, markers for early progenitor cells, ${ }^{26}$ over the first 
A

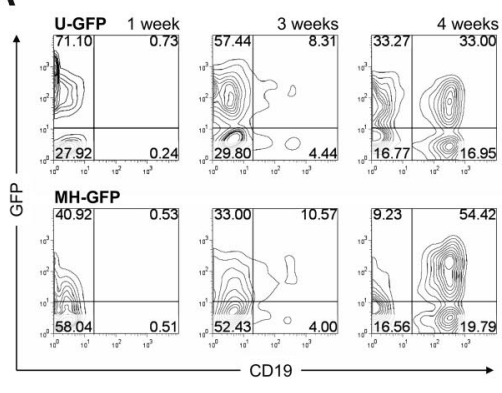

B

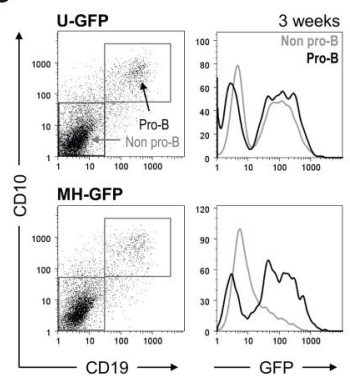

C

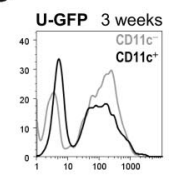
MH-GFP

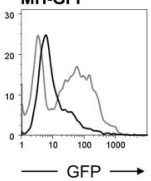

D

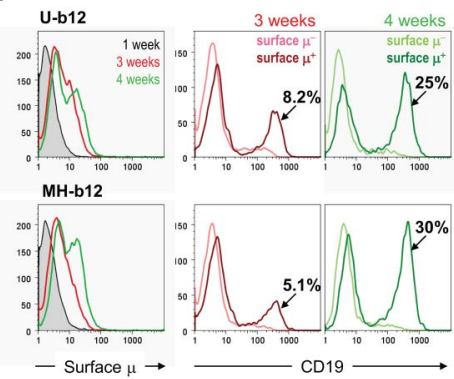

E

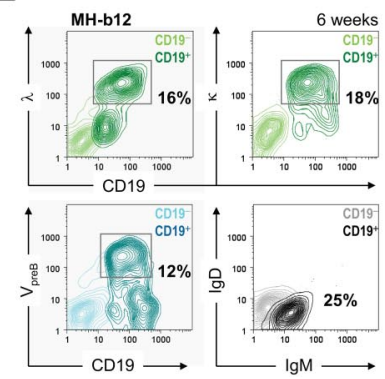

$F$

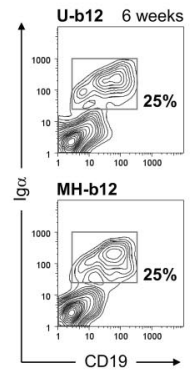

Figure 2. Stage 2: in vitro development of human B cells on stromal cells. (A) HSPCs primed and transduced with either U-GFP (top panels) or MH-GFP (bottom panels) lentiviral constructs were cultured on MS5 stromal cells for the indicated periods of time. The cultures were maintained biweekly as described in "In vitro human B lymphopoiesis culture system." GFP expression and appearance of CD19+ cells were monitored using flow cytometry. (B) Pro-B cells started to appear at 3 weeks of stage 2 , as monitored by the expression of both CD19 and CD10 on the cell surface. When gates were applied to pro-B versus non-pro-B and GFP expression was analyzed in these gates, the $\mathrm{MH}$ promoter showed pro-B cell-specific expression, whereas the ubiquitin promoter did not discriminate between the cells. The lighter lines represent non-pro-B cells; the darker lines represent pro-B cells. (C) Similar analysis was used to compare CD11c ${ }^{+}$dendritic cells to CD11 ${ }^{-}$cells. (D) Surface $\mu$ heavy chain was detected as early as 3 weeks (central panels) into stage 2 and increased at 4 weeks (right panels). The colored labels match the colored lines in the graphs. The percentages shown are those of total live cells. (E) Expression levels of $\lambda$ and $\kappa$ light chains, $V_{\text {preB }}$ surrogate light chain, and $\mu$ and $\delta$ heavy chains were plotted against CD19 expression, indicating a mixture of pre-B and immature B cells at the end of stage 2 . The percentages shown are those of total live cells. (F) CD19+ cells was positive for Ig $\alpha$ at the end of stage 2 ( 6 weeks). When both $\lg \alpha$ and $\lg \beta$ were examined, the percentage of $\lg \alpha^{+}$cells and that of $\lg \beta^{+}$cells was similar. In all analyses, cells carrying EEK-b12 showed a similar phenotype to those with MH-b12 (data not shown). Unless specified, all fluorochrome-conjugated antibodies were purchased from BD Biosciences PharMingen (San Diego, CA) or BioLegend (San Diego, CA). Flow cytometry was performed on a BD FACSCalibur System (BD Biosciences, San Jose, CA), and the results were analyzed using the FlowJo software (TreeStar, Ashland, OR).

3 weeks (Figure S2A). CD13 ${ }^{+}$cells representing the myeloid lineage started to appear as early as 1 week after the initiation of coculture (Figure S2B) because the myeloid fate is presumably the default commitment for HSPCs. ${ }^{27}$ However, the cooperation of B-cell lineage priming and MS5 stromal support induced the generation of CD19+ early B cells between weeks 3 and 4 (Figure 2A). Beyond 4 weeks, B cells continued to form and predominated. The generation of B cells was not affected by transgene expression (Figure S3A). More importantly, although the ubiquitin promoter drove similar levels of GFP expression in both CD19- and CD19+ cells at 4 weeks, the B cell-specific $\mathrm{MH}$ promoter was stronger for expressing GFP in $\mathrm{CD}_{19}{ }^{+}$cells (Figure 2A right panels).

B-cell development proceeds through multiple, well-characterized stages. ${ }^{28} \mathrm{CD} 34^{+}$cells lose stem cell markers, rearrange heavy chain genes, express intracellular heavy chain, and are now pro-B cells. They then gain expression of surrogate light chains and are pre-B cells. Light chain genes then rearrange and become surface-IgM ${ }^{+}$immature $B$ cells. To determine whether stage 2 supported B-cell subpopulations representative of those present in vivo in normal human bone marrow, we evaluated the surface expression of early B-lineage markers. ProB cells, identified by CD19 and CD10 coexpression, appeared after 3 weeks (Figure 2B left panels). These cells were negative for the expression of surrogate light chains, indicating that they were indeed pro-B cells (data not shown). As anticipated, transgene expression driven by a B cell-specific promoter was found in pro-B cells but not other cells (Figure $2 \mathrm{~B}$ right panels). In contrast, $\mathrm{CD} 11 \mathrm{c}^{+}$dendritic cells derived from $\mathrm{MH}-\mathrm{GFP}-$ transduced progenitor cells were negative for GFP (Figure 2C), consistent with the lack of immunoglobulin transcrip- tion in dendritic cells. This indicates that the MH promoter is predominantly active in the B-cell lineage.

After 4 weeks of coculture of transduced cells and MS5 stromal cells, $25 \%$ to $30 \%$ of total cells were $\mathrm{CD} 19^{+} \mu^{+}$, up from $5 \%$ to $8 \%$ at 3 weeks (Figure 2D). At 6 weeks, $\mathrm{CD}^{+} 9^{+}$cell populations consisted of $\mathrm{V}_{\text {preB }}{ }^{+}$pre-B cells and $\kappa / \lambda^{+}$immature B cells (Figure $2 \mathrm{E}$ bottom left and top panels). These cells were $\mu^{+} \delta^{-}$, indicating that they were not mature B cells (Figure 2E bottom right panel). All CD19 ${ }^{+}$cells were also positive for Ig $\alpha$ (Figure $2 \mathrm{~F}$ ), as well as $\operatorname{Ig} \beta$ (data not shown), suggesting that they are capable of signaling through their B-cell receptor or pre-B-cell receptor. These results showed that we have sequentially obtained pro-B cells at 3 to 4 weeks and a mixture of pre-B and immature B cells at the end of stage 2. There was no significant difference in the percentage of $\mathrm{B}$ cells derived among no virus, control vectors (mock or GFP vectors), or b12 constructs (Figure S3A), and neither MH-b12 nor EEK-b12 affected the development of $\mathrm{CD} 19^{+} \mathrm{CD} 10^{+}$pre-B and $\mathrm{CD} 19^{+} \mathrm{CD} 10^{-}$immature $\mathrm{B}$ cells at 6 weeks (Figure S3B), suggesting that the expression of either a secretory IgG or GFP does not interfere with normal B-cell development in the bone marrow. In addition, because the expression of b12 did not block the appearance of endogenous $\mu$ heavy chain or $\kappa / \lambda$ light chains on the cell surface, it is doubtful that the secretory $\operatorname{IgG}$ has allelic excluded endogenous immunoglobulin expression. These results suggest that HSPCs programmed with a secretory neutralizing antibody might develop normally into B cells in the bone marrow. 
A

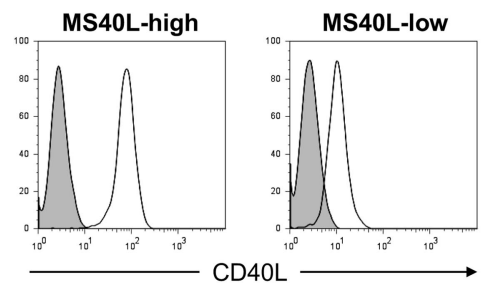

C
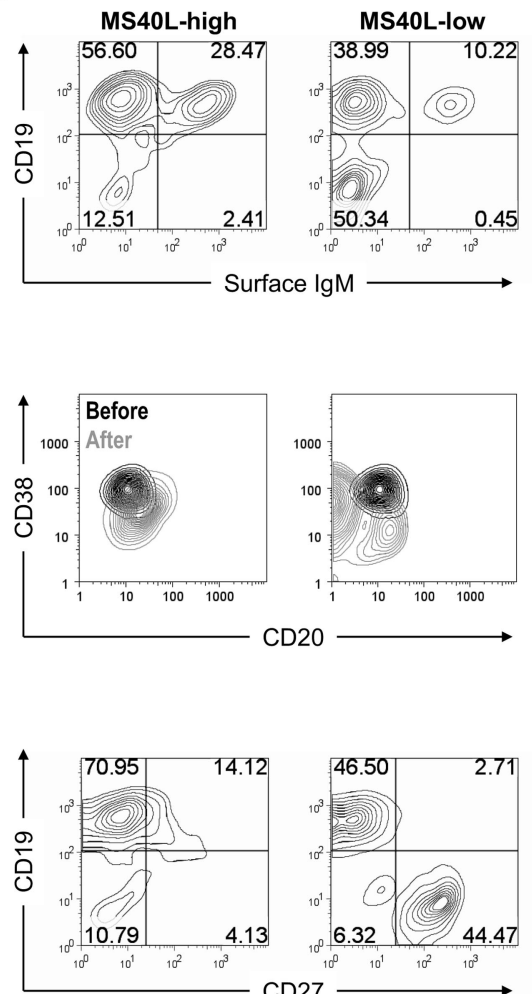

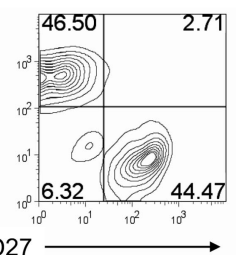

B

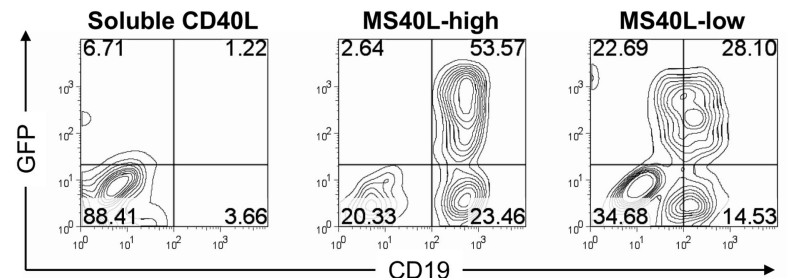

D
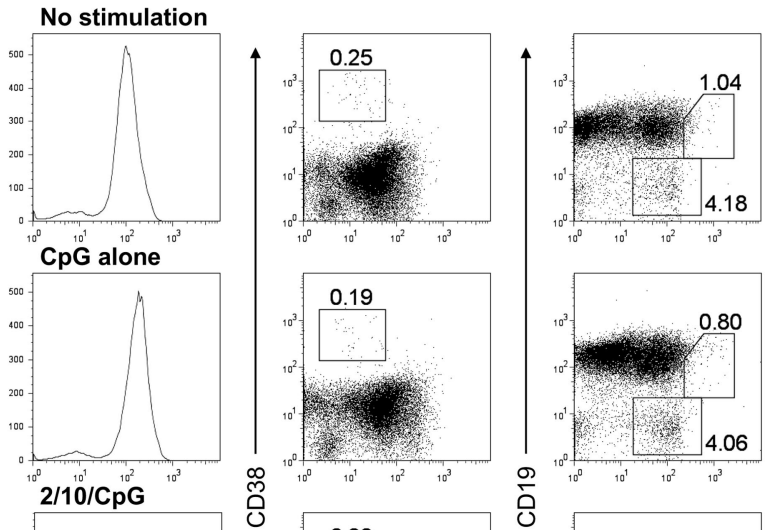

ỡ
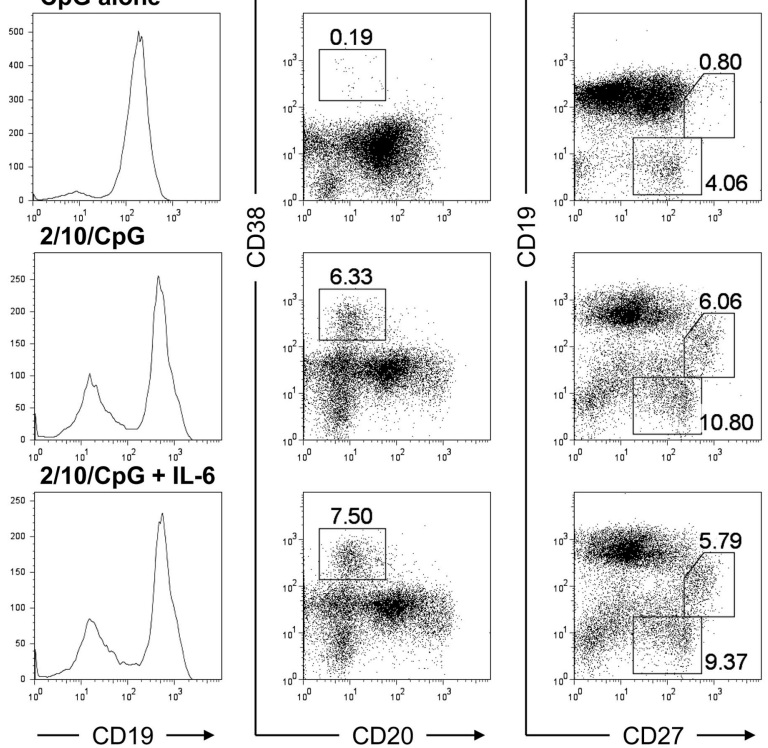

임
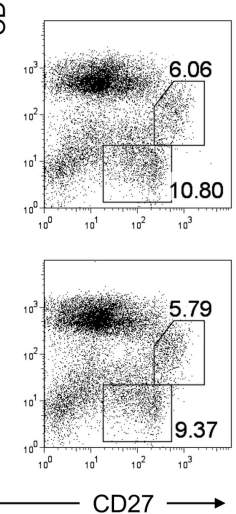

Figure 3. Promotion of plasma cell differentiation using the MS40L-low cell line along with IL-2, IL-10, and CpG. (A) MS5 cells were transduced by FUW-CD40L virus, and 2 single-cell clones (MS40L-high and MS40L-low) were selected based on the expression level of CD40L detected by flow cytometry. The shaded peaks represent parental MS5 cells; open peaks, transduced cells. (B) Stage 2-derived cells carrying the GFP transgene were transferred onto MS40L stable lines (MS40L-high and MS40L-low) and incubated in the presence of IL-2 $(10 \mathrm{ng} / \mathrm{mL})$, IL-10 $(100 \mathrm{ng} / \mathrm{mL})$, and CpG $(2 \mu \mathrm{M})$ for 18 days. The ability of MS40L cell lines to support B-cell activation was compared with that of soluble CD40L $(1 \mu \mathrm{g} / \mathrm{mL})$. Soluble CD40L did not support the survival of B cells, leading to nearly no detection of CD19+GFP+ cells. In contrast, the MS40L cell lines supported the survival and expansion of B cells. (C) The abilities of MS40L-high and MS40L-low to induce plasma cell differentiation were compared as indicated by decreased CD19 and surface IgM expression (top panels), appearance of CD20- CD38 ${ }^{+}$cells (middle panels), and increased CD27 expression (bottom panels). (D) Naive B cells isolated from human peripheral blood were cultured in the presence of MS40L-low and the indicated stimuli (CpG, IL-2, IL-10, and/or IL-6 [50 ng/mL]) for 9 days and stained for flow

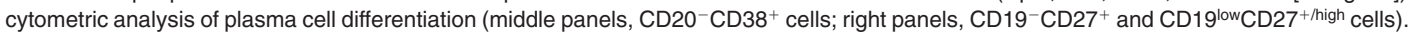

\section{Stage 3 activation and plasma cell differentiation of in vitro-developed human B cells}

To investigate whether the pre-B and immature B cells generated during stage 2 possess the potential to further develop, we transferred them to stage 3 for B-cell activation and plasma cell differentiation. However, as described earlier, the culture conditions for B-cell activation had to be improved because the previous system ${ }^{17}$ did not achieve terminal differentiation of B cells into plasma cells. We extensively tested many stimulatory combinations, and the best results are presented here. Because anchored CD40L might mimic T-cell help for B-cell activation, we generated 2 stable lines of MS5 origin expressing high or low levels of human CD40L on the cell surface, named the MS40L-high or MS40L-low cell lines (Figure 3A). CD40L expression on T-helper cells is up-regulated through the interaction of $\mathrm{T}$ and $\mathrm{B}$ cells, and it provides a survival signal for
B cells. ${ }^{29}$ However, because CD40 ligation also induces apoptosis of both normal and malignant B cells, ${ }^{30}$ we hypothesized that the strength of CD40 ligation was important and tested whether the survival and differentiation of in vitro-derived B cells could be achieved by adjusting the level of anchored CD40L. We found that the anchorage of CD40L was strikingly beneficial for the activation and proliferation of B cells compared with soluble CD40L (Figure 3B) and that MS40L-low cells were better than MS40L-high for inducing stage 2-derived B cells to become plasma cells. Plasma cells, which were most evident at the end of stage 3, were defined by a reduced level of surface CD19 and IgM (Figure 3C top panels), appearance of CD20CD38 ${ }^{+}$cells (Figure 3C middle panels), and an increased level of CD27 (Figure 3C bottom panels). These results showed that a suitable level of anchored CD40L could induce proliferation and terminal differentiation of in vitro-derived B cells into plasma cells. 
A
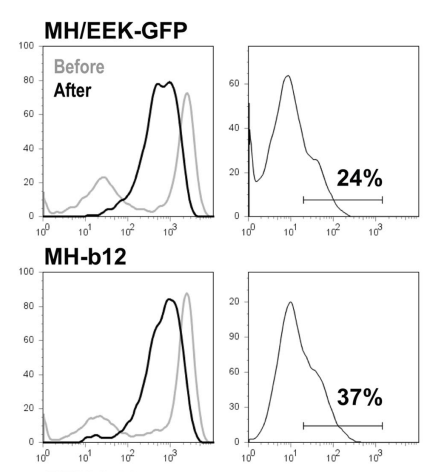

EEK-b12

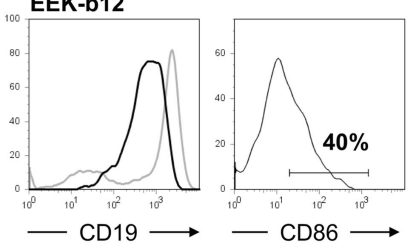

D

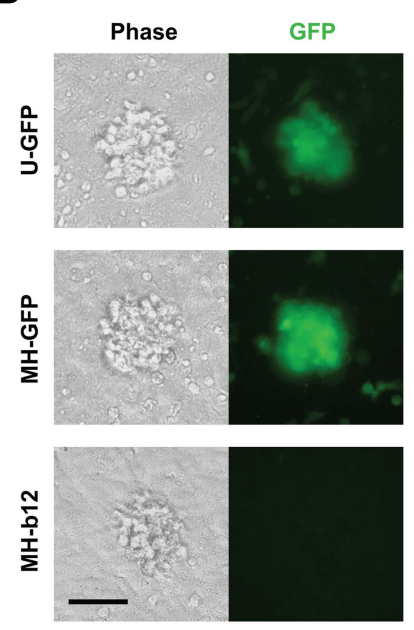

B

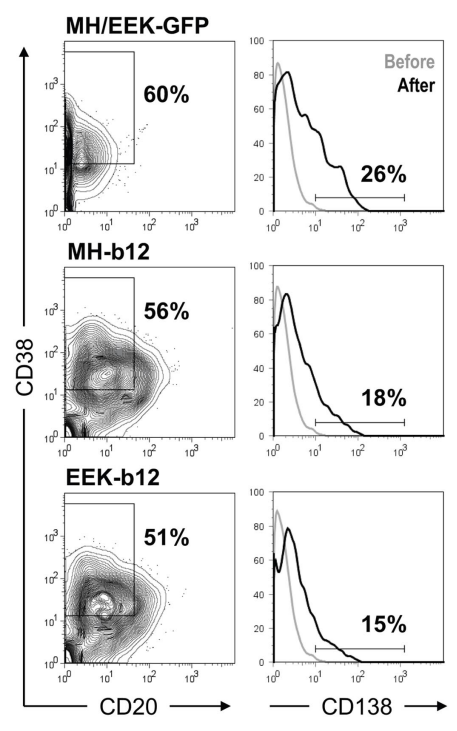

$\mathbf{E}$

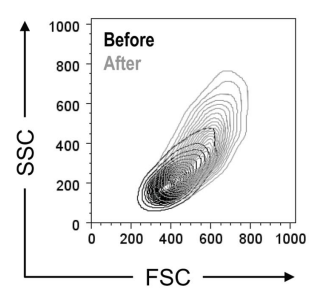

$\mathbf{F}$

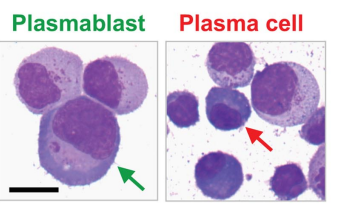

C

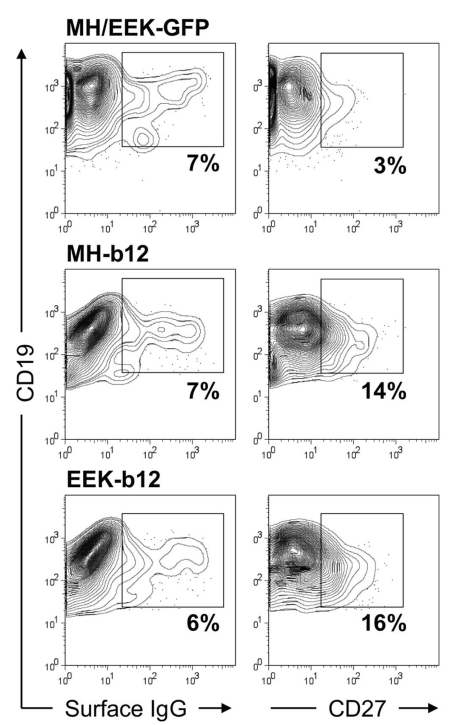

G

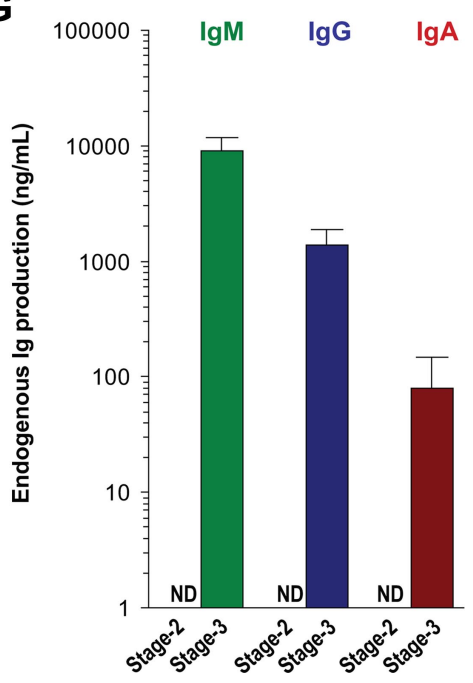

Figure 4. Stage 3: activation and plasma cell differentiation of in vitro-developed human B cells. Cells from stage 2 were transferred onto the MS40L-low monolayer and incubated in the presence of IL-2 (10 ng/mL), IL-10 (100 ng/mL), and CpG (2 $\mu$ M) for 2 to 3 weeks. (A) Comparison of CD19 expression before (lighter lines) and after (darker lines) stage 3 showed an increased percentage of CD19+ cells but a decrease of CD19 intensity. Expression of CD86 is also shown. (B) Regardless of the promoter (MH or EEK) and transgene (GFP or b12), both plasmablasts $\left(\mathrm{CD} 20^{-} \mathrm{CD} 38^{+} \mathrm{CD} 138^{-}\right)$and plasma cells $\left(\mathrm{CD} 20^{-} \mathrm{CD} 38^{+} \mathrm{CD} 138^{+}\right)$were generated. The percentages shown are those of total live cells. (C) Class-switched B cells (surface $\operatorname{lgG}^{+}$) and memory B cells $\left(C D 19^{+} \mathrm{CD} 27^{+}\right.$) were also generated. The percentages shown are those of CD19 ${ }^{+}$cells. (D) B cells from stage 2 proliferated during stage 3 and formed clusters on the MS40L-low monolayer as shown in the phase-contrast and fluorescent images. Bar represents $25 \mu \mathrm{m}$. Cell clusters were visualized by a Nikon epifluorescence microscope equipped with a GFP filter set (4× objective lens). (E) A representative forward (FSC) and side (SSC) scatter graph of CD19+ cells before (darker traces) and after (lighter traces) stage 3 is shown. The cells after stage 3 were larger in size and more granular than those before stage 3. (F) Representative Wright stain images of plasmablasts and plasma cells as indicated by arrows. Bar represents $5 \mu \mathrm{m}$. For Wright stains, single cell suspensions were cytospinned onto slides, air-dried, stained, and examined on an Olympus BX-51 microscope (10× objective lens) and photographed using a Spot Digital Camera. (G) Endogenous levels of IgM, IgG, and IgA production by cells carrying no virus or the GFP transgene at the end of stage 2 and stage 3 were assayed using ELISA. ND indicates not detectable.

However, antigen-independent activation of naive B cells requires signals in addition to CD40L. ${ }^{31}$ In one study, this was achieved with 3 steps of stimulation that included CpG, IL-2, IL-10, IL-15, IL-6, interferon- $\alpha$, and anti-CD40L. ${ }^{32}$ By testing the activation of naive $\mathrm{B}$ cells isolated from human peripheral blood with different stimulatory combinations, we were able to simplify their cocktail to administration of IL-2, IL-10, and CpG once every 3 days. The addition of other components of their cocktail, such as IL-6, did not significantly increase the percentages of antibody-secreting $\mathrm{CD} 20^{-} \mathrm{CD} 38^{+}$and $\mathrm{CD} 19^{-/ \text {low }} \mathrm{CD} 27^{+}$cells (Figure 3D). Whether the pre-B and immature $\mathrm{B}$ cells from stage 2 require differentiation into mature B cells before they were activated requires further investigation.

A detailed phenotypic evaluation of stage 3 cells cultured for 2 to 3 weeks on MS40L-low in the presence of IL-2, IL-10, and $\mathrm{CpG}$ revealed that antibody-secreting plasmablasts and plasma cells were generated from our long-term cultures. Plasmablasts (also called plasma cell precursors) lack CD138 expression ${ }^{33}$; however, both precursor and definitive plasma cells produce large amounts of antibodies. During the differentiation of stage 3 cells, CD19 expression decreased (Figure 4A left panels), whereas the percentages of $\mathrm{CD} 20^{-} \mathrm{CD} 38^{+}$cells (precursor and definitive plasma cells) and $\mathrm{CD} 138^{+}$plasma cells increased (Figure 4B). CD86 
expression was elevated shortly after the initiation of stage 3 (Figure 4A right panels); however, the enhanced level decreased as $\mathrm{B}$ cells switched from proliferating to differentiating into plasma cells (data not shown). Surface IgG expression appeared, whereas the percentage of $\mathrm{CD} 27^{+}$cells increased (Figure 4C), indicating the occurrence of class switching of endogenous $\operatorname{IgM}$ to membranebound IgG and the appearance of the memory cell phenotype. We observed no difference between the plasma cell differentiation of B cells carrying GFP (Figure S4) or b12 lentiviral constructs, and the effects of $\mathrm{MH}$ and EEK promoters on the plasma cell phenotype did not differ (Figure 4A,B), suggesting that the expression of the secretory $\mathrm{IgG}$ transgene does not interfere with plasma cell differentiation. Notably, however, the presence of b12 may be associated with more $\mathrm{CD} 19^{+} \mathrm{CD} 27^{+}$memory cells (Figure $4 \mathrm{C}$ right panels). In addition, clusters formed from B cells carrying the

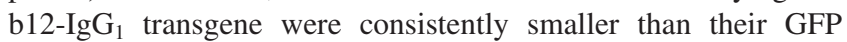
controls (Figure 4D), suggesting that continuous secretion of IgG may interfere with B-cell proliferation. Nevertheless, B cells at the end of stage 3 were larger and more granular compared with those generated from stage 2 (Figure 4E), displayed the morphology of plasmablasts or plasma cells (Figure 4F; for a histologic comparison to normal plasmablasts and plasma cells from human bone marrow, see Figure S5), and produced large amounts of endogenous IgM, IgG, and IgA (Figure 4G). These results showed that we can push stage 2-derived B cells to reach the stage of plasmablasts and plasma cells using a simple combination of IL-2, IL-10, CpG, and MS40L-low and that these antibody-secreting cells were phenotypically and functionally normal regardless of the presence of transgenic b12- $\operatorname{IgG}_{1}$. This indicates that the introduction of a secretory antibody may not interfere with the peripheral/splenic stage of normal B-cell development.

\section{Programming of human B cells to produce the broadly neutralizing anti-HIV antibody, b12-lg $\mathrm{G}_{1}$}

Finally, we asked the key question: Can B cells be programmed through HSPCs to produce the broadly neutralizing anti-HIV antibody, b12? Analysis of the integrated lentivirus in genomic DNA of B cells at different times of the in vitro culture system revealed that the provirus was present throughout B-cell development (Figure 5). B cells at the pre-B stage had lower provirus copy numbers per cell than plasma cells, possibly because of the outgrowth of nonintegrated pre-B cells. Indeed, the number of pre-B cells was approximately 2 times that of plasma cells, leading to lower provirus number at per-cell level. It is probable that the differentiation process positively selected B cells carrying the lentiviral integrations. Importantly, the cells carrying the integrations apparently survived and developed, as the provirus copy numbers per cell at the end of stage 3 , on average, were not statistically different from those of their progenitors $(P=.26)$. This suggests that stable integration of the lentivirus encoding the anti-HIV neutralizing antibody can be maintained from HSPCs to antibody-secreting B cells.

To measure b12 production by B cells in our long-term cultures and distinguish it from endogenous $\mathrm{IgG}$, we used b12-specific ELISA to determine the amount of b12 secretion from both stage 2 and stage 3. During stage 2, a small amount of b12- $\operatorname{IgG}_{1}$ was detected in weekly harvested cell culture supernatants if the b12 transgene had been introduced initially (Figure 6A). The ubiquitin promoter drove a constantly low level of b12 expression. The expression of b12 in response to the $\mathrm{MH}$ promoter was also low but probably coincided with the time when pro-B cells started to appear. Nevertheless, the level of $\mathrm{b} 12-\mathrm{IgG}_{1}$ secreted during stage 2

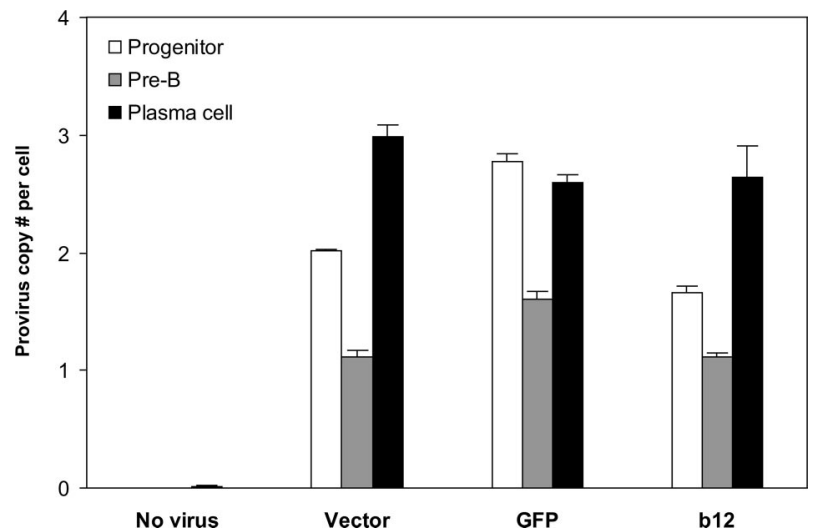

Figure 5. Stable integration of the lentivirus maintained throughout human B-cell development in vitro. Genomic DNA from cells at week 2 and week 4 of stage 2 (representing progenitor and pre-B stages, respectively) and at the end of stage 3 (representing plasma cell stage) was extracted and virus integration was determined as described in "Detection of virus integration." Averaged provirus copy numbers per cell are shown for no virus or different lentiviral constructs originally transduced into $\mathrm{CD}_{3}{ }^{+}$cells. The results are shown as mean plus SE from combined data obtained from experiments for the same transgene (vector only, GFP, or b12; regardless of $U$, $\mathrm{MH}$, or EEK promoters). There were $5,3,6$, and 6 biologic replicates for no virus, vector, GFP, and b12, respectively. The provirus copy numbers per cell at plasma cell stage, on average, were not statistically different from those of their progenitors $(P=.26)$. Student 2-tailed $t$ test was performed using Excel statistical software module (Microsoft, Redmond, WA), and the difference was considered statistically significant when the $P$ value was less than .05 .

was so low that it is unlikely to reach a physiologically relevant level to neutralize the HIV virus. This suggests that the activation of B cells carrying b12 may be required for the production of b12- $\operatorname{IgG}_{1}$ at higher levels because $B$ cells need to be activated to achieve their full potential as professional antibody-producing cells. Indeed, when high levels of endogenous IgM, IgG, and IgA were detected at the end of stage 3 (Figure 6B), we obtained more than $100 \mathrm{ng} / \mathrm{mL}$ of $\mathrm{b} 12$ if the cells had been originally transduced with $\mathrm{MH}-\mathrm{b} 12$, and a strikingly high level of nearly $1.5 \mu \mathrm{g} / \mathrm{mL}$ of b12 in the case of EEK-b12 (Figure 6C). The capacity of a plasma cell's antibody secretion machinery may have limited the total amount of antibody secreted, leading to the reduction of $\operatorname{IgM}$ production from cells carrying EEK-b12 (Figure 6B), when b12-IgG was highly produced from these cells (Figure 6C). Nevertheless, the concentration of $1.5 \mu \mathrm{g} / \mathrm{mL}$ achieved by EEKb12 is comparable with that of endogenous IgG production and, when put into human serum, is enough to achieve more than $90 \%$ neutralization of HIV-1 virus in vitro. ${ }^{34}$ The ubiquitin promoter was relatively weak for driving transgenes in $\mathrm{B}$ cells and thus failed to induce a level of b12- $\operatorname{IgG}_{1}$ comparable with either of the 2 B cell-specific promoters (data not shown). B12- $\operatorname{IgG}_{1}$ was also detectable in the cytoplasm of $\mathrm{B}$ cells carrying the transgene using intracellular costainings of fluorochrome-labeled $\mathrm{gp} 120_{\mathrm{MN}}$ and anti-IgG interacting with the anti-gp120 epitope and $\gamma$ heavy chain constant region of b12- $\mathrm{IgG}_{1}$, respectively (Figure 6D). Collectively, these results showed that, by transducing HSPCs with MH-b12 or EEK-b12 lentiviral constructs and differentiating the transduced cells along B-lineage, human B cells can be programmed to produce the b12-IgG $\mathrm{Ig}_{1}$ neutralizing antibody.

We also asked why the EEK promoter induced a higher level of transgenic b12 production than the $\mathrm{MH}$ promoter. Virus integration did not differ between the 2 promoters (Figure 6E) as both MH-b12 and EEK-b12 viruses were carefully prepared to ensure equally efficient transductions. However, we found that the EEK promoter was more active than the $\mathrm{MH}$ promoter in driving GFP expression in a plasmacytoma cell line (Figure 6F), but not in either Nalm-6 or 
A

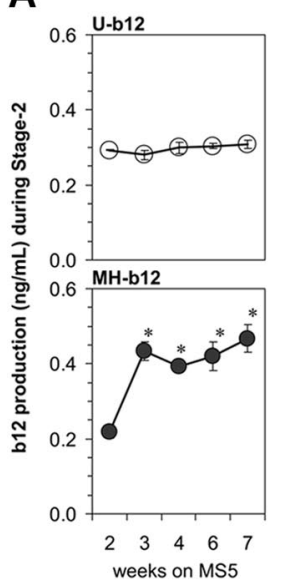

D

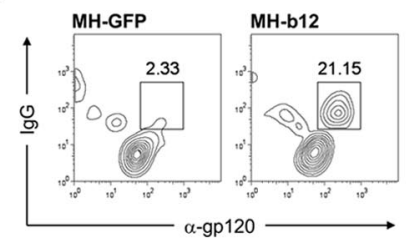

B

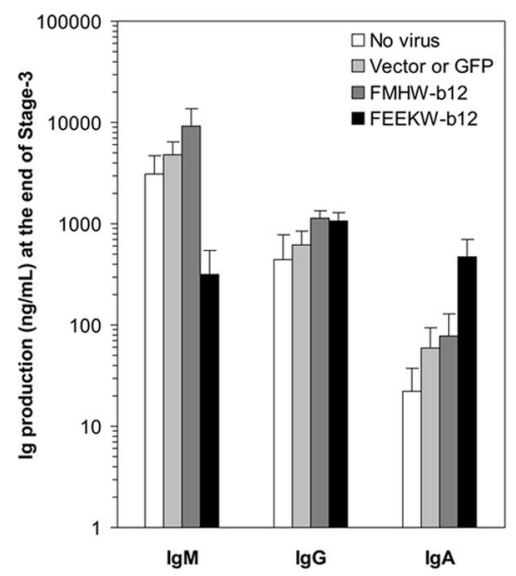

$E$

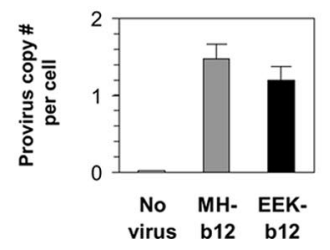

C

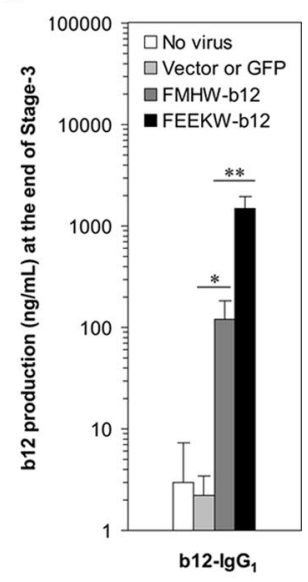

$\mathbf{F}$

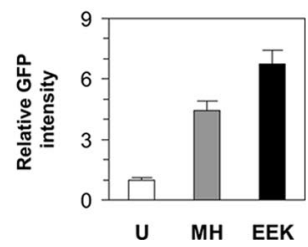

Figure 6. Programming of human B cells to produce the broadly neutralizing anti-HIV antibody, b12-IgG . $^{\text {. }}$ ( ) B12 levels during stage 2 were measured using b12-specific ELISA and are shown by weeks. Note that the culture media were changed biweekly; thus, the data represent the accumulation of the antibody in 3 to 4 days. The results are mean plus or minus SE from 3 independent cultures. * indicates significant difference from week $2(P<.05)$. (B) A total of 50 000 cells of each treatment from stage 2 were transferred to stage 3 of $500 \mu \mathrm{L}$ per well. Total IgM, IgG, and IgA levels were measured, and the results are mean plus $S E$ from 3 independent cultures. "Vector or GFP" represents the averaged effect of empty vectors (FMHW and FEEKW) and GFP-containing vectors (MH-GFP and EEK-GFP). (C) The levels of b12-lgG 1 at the end of stage 3, assayed using b12-specific ELISA, are shown $\left({ }^{\star} P<.02 ;{ }^{\star \star} P<.002\right)$. The bars are color-coded as in panel $\mathrm{B}$. (D) MH-GFP- or MH-b12-transduced HSPCs were cultured through stage 2 and stage 3 , and surface-stained with anti-CD19 antibody and intracellularly stained with anti-IgG antibody and monomeric gp120. Monomeric gp120 ${ }_{\text {MN }}$ was labeled using the Alexa-Fluor-647 Protein Labeling Kit from Invitrogen (Carlsbad, CA). Data were analyzed using flow cytometry and pregated on CD19+ cells. Intracellular proteins recognizing gp120 are identified as $\alpha$-gp 120 . (E) Genomic DNA from progenitor cells (at week 2 of stage 2) derived from $\mathrm{CD}_{3} 4^{+}$cells uninfected or infected by $\mathrm{MH}$-b12 or EEK-b12 virus was extracted and virus integration was determined as described in "Detection of virus integration." Provirus copy numbers per cell are shown as mean plus SE from 3 independent cultures. (F) Dakiki plasmacytoma cells were transduced by U-GFP, MH-GFP, or EEK-GFP lentiviruses. Flow cytometry was performed after 72 hours of incubation and the fold of GFP intensity over the effect of U-GFP (defined as 1$)$ is shown. The difference between MH-GFP and EEK-GFP was significant $(P<.05)$. Student 2-tailed $t$ tests were performed using Microsoft Excel statistical software module and the difference was considered statistically significant when the $P$ value was less than .05 .

Ramos cell lines (data not shown), suggesting that a light chain promoter may preferentially drive the expression of b12 in antibody-secreting plasma cells. This also suggests that plasma cells are good targets for the engineering of neutralizing antibodies to be HIV vaccines because of their natural ability to produce large amounts of antibodies.

\section{Discussion}

In this report, we have used the concept of "instructive immunotherapy," 35 or "engineering immunity," to investigate the potential of a B cell-based anti-HIV vaccination strategy. We showed that the programming of human B cells to provide neutralizing antibodies as HIV vaccines is achievable through lentiviral transduction of HSPCs and differentiation of the transduced cells into antibodysecreting B cells.

To prepare a good in vitro model for our investigation, we first re-created human B lymphopoiesis in vitro based on the culture system reported by Fluckiger et al, ${ }^{17}$ which was modified extensively to achieve an optimal environment for B-cell differentiation. Notably, we used a 5-day pretreatment with IL-3, Flt3 ligand, thrombopoietin, SCF, and G-CSF to commit HSPCs to the B-lineage development and to provide an environment for lentiviral transduction before giving the cells stromal support. In addition, we found a suitable level of anchored CD40L, provided by the cell line MS40L-low, to mimic T-cell help for B-cell activation. Furthermore, we found a simple combination of IL-2, IL-10, and $\mathrm{CpG}$, which, in cooperation with MS40L-low, could activate B cells and differentiate them into antibody-secreting plasmablasts and plasma cells. The improved culture system provided us an excellent tool for B-cell programming.

Our next obstacle was to find a suitable promoter that could drive the expression of transgenic b12- $\operatorname{IgG}_{1}$ in antibody-secreting B cells. Successful cell-specific transgene expression in hematopoietic cells has been achieved for erythroid cells, ${ }^{36} \mathrm{~T}$ cells, ${ }^{37}$ and B cells. ${ }^{38}$ For B cells, the CD19 promoter was shown to direct transgene expression specifically throughout their development in primary and secondary lymphoid organs. ${ }^{38}$ Unfortunately, plasma cells lose the expression of CD19 because of the repression of B-cell lineage-specific activator protein (encoded by Pax-5) by B lymphocyte-induced maturation protein- $1,{ }^{39}$ suggesting that the strength of the CD19 promoter would be dampened when transduced B cells become plasma cells. Thus, we generated 2 synthetic promoters ( $\mathrm{MH}$ and EEK) based on those driving the endogenous expression of immunoglobulins. Both promoters were capable of inducing GFP or b12 expression in B cells without affecting B-cell development. 
In particular, we found that the EEK promoter was favored for transgene expression in plasmablasts and plasma cells, giving rise to a level of $1.5 \mu \mathrm{g} / \mathrm{mL}$ of $\mathrm{b} 12-\mathrm{IgG}_{1}$ production at the end of the in vitro culture system. Although measured by a different ELISA, the level of total endogenous $\operatorname{IgG}$ was quite similar $(\sim 1 \mu \mathrm{g} / \mathrm{mL})$. Thus, the production of total $\mathrm{IgG}$ and $\mathrm{b} 12-\mathrm{IgG}_{1}$ was of the same order of magnitude, suggesting that the synthetic promoter and the endogenous promoter had comparable strengths. Given that HIV-infected people have approximately $20 \mathrm{mg} / \mathrm{mL}$ of endogenous $\operatorname{IgG}^{40,41}$ (double the usual concentration), if $1 \%$ of cells that produce $\mathrm{IgG}$ were transgenic for b12- $\operatorname{IgG}_{1}$, that should yield a serum level as high as $200 \mu \mathrm{g} / \mathrm{mL}$, well above the level needed for neutralization. ${ }^{34,42}$ Another calculation would be to note that there are approximately $10^{12} \mathrm{~B}$ cells in a person; and if each made the $1 \mathrm{pg} /$ day of $\mathrm{IgG}$ that our cells make in vitro $[(1.5 \mu \mathrm{g} / \mathrm{mL} \times 0.5$ $\mathrm{mL}) /(50000$ cells $\times 15$ days $)=1 \mathrm{pg} /$ cell per day], that would yield $1 \mathrm{~g} /$ day of $\mathrm{IgG}$. Because the blood volume is approximately $5 \mathrm{~L}$, that would be a production of $0.2 \mathrm{mg} / \mathrm{mL}$ per day. If $\mathrm{IgG}$ has a half-life of 1 month in the blood, that would give a concentration of $3 \mathrm{mg} / \mathrm{mL}$ of $\operatorname{IgG}$ steady state, within a factor of 3 of the measured amount in human serum $(10 \mathrm{mg} / \mathrm{mL})$. This suggests that our culture system is producing $\mathrm{IgG}$ at a rate comparable with the in vivo rate. Therefore, our results suggest that HIV vaccination could be achieved by autologous transplantation of in vitro-programmed HSPCs, which would develop into antibody-secreting B cells in vivo and provide a continuous supply of anti-HIV-neutralizing antibodies.

It should be emphasized that the system we present here represents only a first step to getting a process that will actually immunize people. For instance, we have used a vector that encodes only a secretory IgG, but the endogenous system makes first a membrane-bound immunoglobulin and then a secreted form. Our system will deliver secretory $\operatorname{IgG}$ continuously, but to have a system like the endogenous one that responds to demand requires a complicated vector. We are working on several such possibilities. Best would be a system, like the natural one, that provides allelic exclusion of the rearrangement of endogenous genes. Another issue that must be considered is the ability of the virus to escape antibody attack by mutation, which may necessitate the use of multiple antibodies. If such a procedure were to be considered for impoverished populations, another serious limitation would be the cost of the procedure.

Passive transfer of high-titered neutralizing antibodies as vaccines has been shown to block simian/HIV infection in macaques $^{42,43}$ and HIV infection in hu-PBL-SCID mice. ${ }^{11,44}$ However, antibodies transferred must remain at high levels to prevent the establishment of infection. In addition, passive immunization for HIV has a significant drawback. It would be cost-prohibitive and impractical to frequently administer antibody preparations to large numbers of people for an indefinite period of time. In contrast, the gene therapy method to provide HIV vaccination poses no restriction on the duration of administration or the possibility to deliver any engineered antibodies or antibody-like proteins that may be more potent in fighting HIV than natural antibodies. These engineered molecules include antibodies with enhanced antibodydependent cell-mediated cytotoxicity ${ }^{45}$ and those with dual ${ }^{46}$ or even multiple-epitope-binding ability. Our approach uses HSPCs to provide continuous supplies of such molecules and allows for predetermination of affinity and specificity before immunization. Furthermore, certain anti-HIV-neutralizing antibodies have demonstrated synergy when combined together. ${ }^{47}$ Thus, the introduction of several neutralizing antibodies by lentiviral transduction may be a good strategy to reduce the total amount of antibodies needed to exert a protective in vivo effect. Finally, the administration of a mixture of effective antibodies with several specificities is also valuable for overcoming the development of viral escape mutants. The HIV virus evolves very rapidly; however, in established infection of some persons, the continuous exposure to antigen provides the opportunity for the selection of antibodies capable of recognizing many viral escape mutants. ${ }^{48}$ These antibodies, if administered as a vaccination mixture before the onset of infection, are clearly beneficial in preventing HIV evolution.

\section{Acknowledgments}

The authors thank D. Burton (Scripps Research Institute, La Jolla, CA) for providing b12 variable regions, G. Crooks (University of Southern California) for MS5 cells, J. Klein (California Institute of Technology) for monomeric gp $120_{\mathrm{MN}}$, and M. Boldin (California Institute of Technology) for the THP-1 cell line with integrated FUW. The authors also thank A. West, P. Peiris, and D. Rao (California Institute of Technology) for Biacore analysis, pseudovirus neutralization assay and microscopy, respectively; and R. Diamond for the use of Flow Cytometry Core Facility at California Institute of Technology.

This study was supported by the Bill and Melinda Gates Foundation (Seattle, WA) through the Grand Challenges in Global Health Initiative (D.B.).

\section{Authorship}

Contribution: X.M.L. designed the study; X.M.L. and E.M. performed the experiments; R.M.O. and P.W. prepared plasmids; D.B. and L.Y. supervised the study; and X.M.L. prepared the manuscript.

Conflict-of-interest disclosure: The authors declare no competing financial interests.

Correspondence: David Baltimore and Lili Yang, Division of Biology, M/C 147-75, California Institute of Technology, $1200 \mathrm{E}$ California Blvd, Pasadena, CA 91125; e-mail: baltimo@ caltech.edu or liyang@caltech.edu.

\section{References}

1. Douek DC, Kwong PD, Nabel GJ. The rational design of an AIDS vaccine. Cell. 2006;124:677681.

2. Letvin NL. Progress and obstacles in the development of an AIDS vaccine. Nat Rev Immunol. 2006;6:930-939.

3. Pitisuttithum P, Gilbert P, Gurwith M, et al. Randomized, double-blind, placebo-controlled efficacy trial of a bivalent recombinant glycoprotein 120 HIV-1 vaccine among injection drug users in Bangkok, Thailand. J Infect Dis. 2006;194:1661-1671.

4. Watkins DI, Burton DR, Kallas EG, Moore JP, Koff
WC. Nonhuman primate models and the failure of the Merck HIV-1 vaccine in humans. Nat Med. 2008;14:617-621.

5. Wyatt R, Sodroski J. The HIV-1 envelope glycoproteins: fusogens, antigens, and immunogens. Science. 1998;280:1884-1888.

6. Karlsson Hedestam GB, Fouchier RA, Phogat S Burton DR, Sodroski J, Wyatt RT. The challenges of eliciting neutralizing antibodies to HIV-1 and to influenza virus. Nat Rev Microbiol. 2008;6:143155.

7. Binley JM, Wrin T, Korber B, et al. Comprehen- sive cross-clade neutralization analysis of a pane of anti-human immunodeficiency virus type 1 monoclonal antibodies. J Virol. 2004;78:1323213252.

8. Pantophlet R, Burton DR. GP120: target for neutralizing HIV-1 antibodies. Annu Rev Immunol. 2006;24:739-769.

9. Pantophlet R, Ollmann Saphire E, Poignard P, Parren PW, Wilson IA, Burton DR. Fine mapping of the interaction of neutralizing and nonneutralizing monoclonal antibodies with the CD4 binding site of human immunodeficiency virus type 1 gp120. J Virol. 2003;77:642-658. 
From www.bloodjournal.org at CALIFORNIA INST TECH/MILLIKAN LIBRARY on March 13, 2009. For personal

10. Kessler JA 2nd, McKenna PM, Emini EA, et al. Recombinant human monoclonal antibody IgG1b12 neutralizes diverse human immunodeficiency virus type 1 primary isolates. AIDS Res Hum Retroviruses. 1997;13:575-582.

11. Parren PW, Ditzel HJ, Gulizia RJ, et al. Protection against HIV-1 infection in hu-PBL-SCID mice by passive immunization with a neutralizing human monoclonal antibody against the gp120 CD4binding site. AIDS. 1995;9:F1-F6.

12. Veazey RS, Shattock RJ, Pope M, et al. Prevention of virus transmission to macaque monkeys by a vaginally applied monoclonal antibody to HIV-1 gp120. Nat Med. 2003;9:343-346.

13. Barbas CF 3rd, Collet TA, Amberg W, et al. Molecular profile of an antibody response to HIV-1 as probed by combinatorial libraries. J Mol Biol. 1993;230:812-823.

14. Szymczak AL, Workman CJ, Wang Y, et al. Correction of multi-gene deficiency in vivo using a single "self-cleaving" 2 A peptide-based retroviral vector. Nat Biotechnol. 2004;22:589-594.

15. Lois C, Hong EJ, Pease S, Brown EJ, Baltimore D. Germline transmission and tissue-specific expression of transgenes delivered by lentiviral vectors. Science. 2002;295:868-872.

16. Pear WS, Nolan GP, Scott ML, Baltimore D. Production of high-titer helper-free retroviruses by transient transfection. Proc Natl Acad Sci U S A. 1993;90:8392-8396.

17. Fluckiger AC, Sanz E, Garcia-Lloret M, et al. In vitro reconstitution of human $B$-cell ontogeny: from CD34(+) multipotent progenitors to lg-secreting cells. Blood. 1998;92:4509-4520.

18. Selvarajah S, Puffer B, Pantophlet R, Law M, Doms RW, Burton DR. Comparing antigenicity and immunogenicity of engineered gp120. J Virol. 2005;79:12148-12163.

19. Brussel A, Delelis O, Sonigo P. Alu-LTR real-time nested PCR assay for quantifying integrated HIV-1 DNA. Methods Mol Biol. 2005;304:139154.

20. Butler SL, Hansen MS, Bushman FD. A quantitative assay for HIV DNA integration in vivo. Nat Med. 2001;7:631-634.

21. Hirayama F, Lyman SD, Clark SC, Ogawa M. The flt3 ligand supports proliferation of lymphohematopoietic progenitors and early B-lymphoid progenitors. Blood. 1995;85:1762-1768.

22. Grassinger J, Mueller G, Zaiss M, KunzSchughart LA, Andreesen R, Hennemann B. Differentiation of hematopoietic progenitor cells towards the myeloid and B-lymphoid lineage by hepatocyte growth factor (HGF) and thrombopoi- etin (TPO) together with early acting cytokines. Eur J Haematol. 2006;77:134-144.

23. Ohkawara Jl, Ikebuchi K, Fujihara M, et al. Culture system for extensive production of CD19+lgM + cells by human cord blood CD34+ progenitors. Leukemia. 1998;12:764-771.

24. Saeland S, Duvert V, Pandrau D, et al. Interleukin-7 induces the proliferation of normal human B-cell precursors. Blood. 1991;78:2229-2238.

25. Hao QL, Shah AJ, Thiemann FT, Smogorzewska EM, Crooks GM. A functional comparison of CD34 + CD38- cells in cord blood and bone marrow. Blood. 1995;86:3745-3753.

26. Messner HA. Assessment and characterization of hemopoietic stem cells. Stem Cells. 1995; 13(suppl 3):13-18.

27. Iwasaki H, Akashi K. Myeloid lineage commitment from the hematopoietic stem cell. Immunity. 2007; 26:726-740.

28. Chen J, Alt FW. Gene rearrangement and B-cell development. Curr Opin Immunol. 1993;5:194200.

29. Kehry MR. CD40-mediated signaling in B cells: balancing cell survival, growth, and death. $\mathrm{J} \mathrm{Im-}$ munol. 1996:156:2345-2348.

30. Lens SM, Tesselaar K, den Drijver BF, van Oers $\mathrm{MH}$, van Lier RA. A dual role for both CD40-ligand and TNF-alpha in controlling human B cell death. J Immunol. 1996;156:507-514.

31. Lanzavecchia A, Bernasconi N, Traggiai E, Ruprecht CR, Corti D, Sallusto F. Understanding and making use of human memory B cells. Immunol Rev. 2006;211:303-309.

32. Huggins J, Pellegrin T, Felgar RE, et al. CpG DNA activation and plasma cell differentiation of CD27- naive human B cells. Blood. 2007;109: 1611-1619.

33. Arce S, Luger E, Muehlinghaus G, et al. CD38 low IgG-secreting cells are precursors of various CD38 high-expressing plasma cell populations. J Leukoc Biol. 2004;75:1022-1028.

34. Burton DR, Pyati J, Koduri R, et al. Efficient neutralization of primary isolates of HIV-1 by a recombinant human monoclonal antibody. Science. 1994;266:1024-1027.

35. Yang $L$, Baltimore D. Long-term in vivo provision of antigen-specific T cell immunity by programming hematopoietic stem cells. Proc Natl Acad Sci U S A. 2005; 102:4518-4523.

36. Grande A, Piovani B, Aiuti A, Ottolenghi S, Mavilio F, Ferrari G. Transcriptional targeting of retroviral vectors to the erythroblastic progeny of transduced hematopoietic stem cells. Blood. 1999;93: 3276-3285.
37. Marodon G, Mouly E, Blair EJ, Frisen C, Lemoine FM, Klatzmann D. Specific transgene expression in human and mouse CD4 + cells using lentiviral vectors with regulatory sequences from the CD4 gene. Blood. 2003;101:3416-3423.

38. Werner M, Kraunus J, Baum C, Brocker T. B-cellspecific transgene expression using a self-inactivating retroviral vector with human CD19 promoter and viral post-transcriptional regulatory element. Gene Ther. 2004;11:992-1000.

39. Lin $\mathrm{KI}$, Angelin-Duclos $\mathrm{C}$, Kuo TC, Calame K. Blimp-1-dependent repression of Pax-5 is required for differentiation of $B$ cells to immunoglobulin M-secreting plasma cells. Mol Cell Biol. 2002;22:4771-4780.

40. Lane HC, Masur H, Edgar LC, Whalen G, Rook $\mathrm{AH}$, Fauci AS. Abnormalities of B-cell activation and immunoregulation in patients with the acquired immunodeficiency syndrome. $\mathrm{N}$ Engl J Med. 1983;309:453-458.

41. Mizuma H, Zolla-Pazner S, Litwin S, et al. Serum IgD elevation is an early marker of B cell activation during infection with the human immunodeficiency viruses. Clin Exp Immunol. 1987;68:5-14

42. Parren PW, Marx PA, Hessell AJ, et al. Antibody protects macaques against vaginal challenge with a pathogenic $\mathrm{R} 5$ simian/human immunodeficiency virus at serum levels giving complete neutralization in vitro. J Virol. 2001;75:8340-8347.

43. Nishimura $Y$, Igarashi T, Haigwood NL, et al. Transfer of neutralizing IgG to macaques $6 \mathrm{~h}$ but not $24 \mathrm{~h}$ after SHIV infection confers sterilizing protection: implications for HIV-1 vaccine development. Proc Natl Acad Sci U S A. 2003;100: 15131-15136.

44. Gauduin MC, Parren PW, Weir R, Barbas CF, Burton DR, Koup RA. Passive immunization with a human monoclonal antibody protects hu-PBLSCID mice against challenge by primary isolates of HIV-1. Nat Med. 1997;3:1389-1393.

45. Lazar GA, Dang W, Karki S, et al. Engineered antibody Fc variants with enhanced effector function. Proc Natl Acad Sci U S A. 2006;103:40054010.

46. van de Winkel JG, Bast B, de Gast GC. Immunotherapeutic potential of bispecific antibodies. Immunol Today. 1997;18:562-564.

47. Zwick MB, Wang M, Poignard P, et al. Neutralization synergy of human immunodeficiency virus type 1 primary isolates by cocktails of broadly neutralizing antibodies. J Virol. 2001;75:1219812208.

48. Burton DR, Stanfield RL, Wilson IA. Antibody vs HIV in a clash of evolutionary titans. Proc Natl Acad Sci U S A. 2005;102:14943-14948. 